\title{
Closed cervix is associated with more severe illness in dogs with pyometra
}

Supranee Jitpean ${ }^{1,2^{*}}$ (D) Aime Ambrosen ${ }^{2}$, Ulf Emanuelson ${ }^{2}$ and Ragnvi Hagman ${ }^{2}$

\begin{abstract}
Background: Pyometra, a life-threatening bacterial infection of the uterus, is classified as open or closed depending on the functional patency of the cervix i.e. presence or absence of vaginal discharge. In closed cervix pyometra, pus and bacterial products accumulate in the uterus, which is thought to induce a more severe illness. The aim of this study was to investigate whether disease severity or outcome differed in dogs with open or closed cervix pyometra.

Results: Prospectively collected data from 111 female dogs diagnosed with pyometra at the University Animal Hospital, Swedish University of Agricultural Sciences, Uppsala, intermittently during 2005-2012 was analyzed. Seventy-two dogs (65\%) had open cervix, whereas 39 dogs (35\%) had closed cervix. Differences between the two groups were explored by Wilcoxon Two Sample Test for continuous variables and Chi-square or Fisher's exact test for categorical variables. $P<0.05$ was considered significant.

In dogs with open cervix the median age was 9.0 years and the median weight $26.0 \mathrm{~kg}$. In dogs with closed cervix the median age was 9.6 years and the median weight $25.0 \mathrm{~kg}$, with no significant differences between the groups ( $p=0.69$ and 0.24 , respectively). Five dogs (4.5\%) died, all with open cervix, and 16 dogs (14\%) had complications. The general physical condition was moderately or severely depressed in 30\% (21/71) of dogs with open cervix (severely depressed in 4 dogs, moderately depressed in 17 dogs) and in 56\% (22/39) of dogs with closed cervix (severely depressed in 3 dogs, moderately depressed in 19 dogs). The general physical condition was mildly depressed in 41 dogs with open cervix and 16 dogs with closed cervix, whereas it was normal in nine dogs with open cervix and one dog with closed cervix. None of the included dogs had very severely depressed general physical condition or were non-responsive.

Leukocytosis, neutrophilia, monocytosis and moderately to severely depressed general condition was more commonly found in dogs with closed cervix $(p=0.003, p=0.008, p=0.003$ and $p=0.006$, respectively). Sepsis was more commonly present in closed cervix pyometra (77\%, 30/39 dogs) compared to open cervix pyometra $(51 \%, 36 / 71$ dogs) $(p=0.007)$. Presence of prolonged postoperative hospitalization did not differ significantly between the two groups.

Conclusions: In dogs with closed cervix, sepsis was more common, the general physical condition more often moderately to severely depressed and leukocytosis, neutrophilia and monocytosis more frequently found. The results showed that closed cervix was associated with a more severe illness than open cervix at admission but not with poorer outcome as measured by postoperative hospitalization. These findings may be clinically valuable for optimizing monitoring and treatments in dogs with the disease.
\end{abstract}

Keywords: SIRS, Sepsis, Hematology, Uterine infection, Dogs

\footnotetext{
* Correspondence: supranee.jitpean@slu.se

${ }^{1}$ Department of Surgery and Theriogenology, Faculty of Veterinary Medicine,

Khon Kaen University, Khon Kaen 40002, Thailand

${ }^{2}$ Department of Clinical Sciences, Swedish University of Agricultural Sciences,

Box 7054SE-750 07 Uppsala, Sweden
}

(c) The Author(s). 2017 Open Access This article is distributed under the terms of the Creative Commons Attribution 4.0 International License (http://creativecommons.org/licenses/by/4.0/), which permits unrestricted use, distribution, and reproduction in any medium, provided you give appropriate credit to the original author(s) and the source, provide a link to the Creative Commons license, and indicate if changes were made. The Creative Commons Public Domain Dedication waiver (http://creativecommons.org/publicdomain/zero/1.0/) applies to the data made available in this article, unless otherwise stated. 


\section{Background}

One of the most frequent reproductive organ disorders in female dogs is pyometra, which affects on average nearly $20 \%$ of all intact bitches before 10 years of age [1]. The disease is associated with inflammation and infection of the uterus leading to generalized illness. The disease often generates systemic inflammatory response syndrome (SIRS), defined as sepsis when initiated by infection [2-5]. Gramnegative bacteria are most commonly isolated from pyometra uteri and foremost Escherichia coli (E. coli). Moreover, Gram-negative bacteria contain endotoxin which is released into the circulation during bacterial growth and death, and endotoxin is a potent inducer of inflammation [6, 7]. Effects of sepsis and endotoxaemia can further cause multi-organ dysfunctions in pyometra, but despite being a potentially life-threatening illness, the mortality is relatively low, 3$10 \%[8,9]$. The safest and most efficient treatment is surgical removal of the infected uterus and ovaries, i.e. ovariohysterectomy (OHE). Pyometra is classified clinically as closed (without vaginal discharge) or open cervix pyometra (with vaginal discharge) depending on the functional patency of the cervix. If the cervix is closed, the pus and bacterial products remain in the uterus, which is believed to lead to a more serious illness compared to when there is some drainage via the cervix [10]. The preliminary diagnosis of pyometra is determined by case history data, physical examination findings and laboratory test results in combination with radiography or/and ultrasonography showing a fluid-filled enlarged uterus. Clinical signs commonly present in pyometra include depression, anorexia, polydipsia/polyuria, vomiting and vaginal discharge $[9,11,12]$. Leukocytosis, neutrophilia with a left shift, monocytosis and anaemia are frequently observed [4, 9, 13]. Elevated creatinine and blood urea nitrogen [11], proteinuria, hypoalbuminemia, hypercholesterolaemia, increased serum alkaline phosphatase (ALP) [14, 15], and coagulation impairment [16] have also been reported. In cases presented without vaginal discharge, it may be more difficult to recognize the disease at an early stage because most other signs of illness are unspecific. Consequently the disease could have been progressing for a longer time before treatment when being diagnosed in dogs with closed cervix pyometra which may contribute to the general assumption of a more severe illness in such cases [17]. The aim of this study was to test the hypothesis that closed cervix leads to more severe illness by investigating whether disease severity and outcome or presence of complications differ between dogs with open or closed cervix pyometra as determined by clinical and laboratory findings.

\section{Results}

Open versus closed cervix pyometra

Thirty-nine (35\%) of the dogs were diagnosed with closed cervix pyometra whereas 72 dogs (65\%) were diagnosed with open cervix pyometra. In dogs with open cervix the median age was 9.0 years and the median weight $26.0 \mathrm{~kg}$. In dogs with closed cervix the median age was 9.6 years and the median weight $25.0 \mathrm{~kg}$. The differences between the two groups were not significant ( $p=0.69$ and 0.24 , respectively).

\section{Mortality and complications}

Of the 111 dogs, five (4.5\%) died, whereof one was euthanized because of mammary tumours and another because of stump pyometra and concurrent severe illness diagnosed 20 days postoperatively, and the three other died one day after surgery due to miscellaneous causes (Table 1). All these pyometra cases had open cervix.

Complications were found in 16 dogs (14\%, 16/111). The complications were detected in 4 of the 39 dogs (10\%) with closed cervix pyometra and in 12 of the 72 dogs $(17 \%)$ with open cervix pyometra. The proportion of dogs with complications did not differ significantly between the two groups.

Peritonitis with associated uterine rupture was observed in four dogs prior to surgery, and in five dogs after surgery, peritonitis without obvious uterine rupture was observed. Other complications included postoperative wound infection, conjunctivitis, chronic pyelonephritis, urinary tract infection and myocarditis/disseminated intravascular coagulation (Table 2). Additionally, one dog with open cervix pyometra required resuscitation during surgery.

\section{Prolonged postoperative hospitalization}

The proportion and number of dogs that required prolonged hospitalization did not differ between dogs with open $(36 \%, n=25 / 69)$ and closed cervix pyometra $(24 \%, n$ $=9 / 37)(p=0.2)$. Most dogs $(61 \%, n=71 / 105)$ with or without sepsis ( $n=33$ and $n=38$, respectively) required normal postoperative hospitalization (1-2 days). Reported prolonged postoperative hospitalization, defined as $\geq$

Table 1 Cause of death in the five bitches that died in present study

Bitch Closed/open cervix Cause of death

no. pyometra

1 open Euthanasia due to concomitant mammary tumours

2 open Euthanasia 20 days after surgery due to stump pyometra and severe illness

3 open Died one day after surgery due to severe

4 open Died one day after surgery due to concomitant myocarditis and disseminated intravascular coagulation reasons and concomitant peritonitis 
Table 2 Complications detected in 16 surgically treated bitches with pyometra with open or closed cervix

\begin{tabular}{lll}
\hline Type of complication & $\begin{array}{l}\text { Closed } \\
\text { cervix (n) }\end{array}$ & $\begin{array}{l}\text { Open } \\
\text { cervix (n) }\end{array}$ \\
\hline $\begin{array}{l}\text { Uterine rupture and peritonitis diagnosed } \\
\text { prior to surgery }\end{array}$ & 1 & 3 \\
$\begin{array}{l}\text { Postoperative peritonitis without obvious } \\
\text { uterine rupture }\end{array}$ & 1 & 4 \\
Postoperative wound infection & 1 & 1 \\
Conjunctivitis & 1 & 1 \\
Chronic pyelonephritis & 0 & 1 \\
Urinary tract infection & 0 & 1 \\
Myocarditis and disseminated intravascular & 0 & 1 \\
coagulation & & \\
\hline
\end{tabular}

3 days, did not differ between dogs with sepsis (39\%, $n=$ $24 / 62)$ and dogs without sepsis $(23 \%, n=10 / 43)(p=0.09)$.

\section{Systemic inflammatory response syndrome}

Sepsis (systemic inflammatory response syndrome, SIRS, induced by infection) was more common in dogs with closed cervix pyometra than in dogs with open cervix pyometra $(p=0.007)$ (Table 3$)$.

\section{Case history and physical examination findings}

Moderately to severely depressed general condition was more common in dogs with closed cervix compared to dogs with open cervix $(p=0.006)$ (Table 3$)$. Anorexia, polydipsia/polyuria, vomiting, and moderate to severe dehydration did not differ significantly between the two groups $(p \geq 0.05)$ (Table 3$)$.

\section{Hematology and serum biochemistry test results}

Leukocytosis, neutrophilia and monocytosis were more common in dogs with closed cervix pyometra compared to dogs with open cervix pyometra $(p=0.003, p=0.008$, and 0.003 , respectively) (Table 3 ). Furthermore, total white blood cell count (WBC), segmented neutrophils and monocyte numbers were significantly higher in dogs with closed cervix pyometra compared to dogs with open cervix pyometra $(p<0.05)$ (Table 4$)$.

\section{Discussion}

Sixty-five percent of the dogs included the present study were diagnosed with open cervix pyometra. That open cervix is more common than closed cervix in pyometra is in accordance with the results of our previous study in which over three-quarter of dogs with pyometra were diagnosed as open cervix pyometra [9]. In the present study, sepsis was diagnosed in $59 \%$ of the dogs, i.e. the majority of pyometra cases, which is in agreement with other studies of dogs with the disease using the same criteria [3, 18, 19]. Furthermore, sepsis was more common in dogs with closed cervix pyometra compared to open cervix pyometra. These results support the general belief that dogs with pyometra without vaginal discharge are more severely ill compared to dogs with open cervix pyometra and vaginal discharge [17]. Sepsis was, however, not associated with worst outcome as measured by prolonged postoperative hospitalization or presence of complications in the present study. This finding is not in line with a study in dogs with pyometra in which SIRS was associated with prolonged hospitalization after surgical treatment [3]. Sepsis has also been associated with a poorer outcome i.e. increased hospitalization or higher risk of mortality in humans $[20,21]$. It is difficult to explain the different results in studies of pyometra, because the same criteria were used to define dogs with sepsis. However, the selected criteria for SIRS with a sensitivity of $97 \%$ and specificity of $64 \%$ [22], may lead to the inclusion of $36 \%$ non-septic dogs in the septic group, and more specific SIRS criteria or a defined gold standard for diagnosing sepsis would be valuable for future studies.

In dogs with closed cervix pyometra, a moderately to severely depressed general condition was more commonly detected at admission than in dogs with open cervix. This might indicate that closed cervix pyometra would be more likely to have a poor outcome, because previously it was shown that dogs with pyometra and moderately to severely depressed general condition had a seven-fold increased risk of having a prolonged postoperative hospitalization [9]. More severely depressed general condition has also been associated with septic peritonitis [9]. Despite closed cervix not being associated with prolonged postoperative hospitalization or presence of complications in the current study, it is important to be aware that a more severe disease in closed cervix pyometra cases at admission can be expected.

Leukocytosis, neutrophilia and monocytosis were more commonly found in dogs with closed cervix pyometra, reflecting the higher amount of inflammatory response initiated by disease. Not only the amount but also the duration of leukocytosis may indicate prognosis because in human patients with persistent leukocytosis there is a high risk of developing infection [23, 24]. Furthermore, leukocytosis has been shown to indicate poor outcome as measured by mortality and duration of hospitalization whether with or without infection in both humans and dogs [25-28]. However, leukopaenia has also been shown to be associated with a peritonitis and prolonged hospitalization in dogs with pyometra [9].

The serum concentrations of creatinine and BUN did not differ significantly between the two groups and most dogs were within the normal range for both analyses. That in the present study only a few dogs with the disease were extremely ill and had elevated serum 
Table 3 Case history data, clinical and laboratory findings, SIRS status and presence of prolonged hospitalization in dogs with open cervix pyometra or closed cervix pyometra with data recorded in each parameter

\begin{tabular}{|c|c|c|c|c|c|}
\hline \multirow[t]{2}{*}{ Variable } & \multicolumn{2}{|c|}{ Open cervix pyometra /number of cases } & \multicolumn{2}{|c|}{ Closed cervix pyometra /number of cases } & \multirow[t]{2}{*}{$p$ value $^{*}$} \\
\hline & $n$ & (\%) & $n$ & (\%) & \\
\hline Case history Anorexia & $39 / 72$ & 54 & $24 / 39$ & 62 & 0.7 \\
\hline \multicolumn{6}{|l|}{ General physical condition } \\
\hline Normal or mild depression & $50 / 71$ & 70 & $17 / 39$ & 43 & \multirow[t]{2}{*}{0.006} \\
\hline Moderate or severe depression & $21 / 71$ & 30 & $22 / 39$ & 56 & \\
\hline Polydipsia & $39 / 72$ & 54 & $24 / 39$ & 62 & 0.5 \\
\hline Polyuria & $37 / 72$ & 51 & $22 / 39$ & 56 & 0.7 \\
\hline Vomiting & $13 / 67$ & 19 & $9 / 36$ & 25 & 0.6 \\
\hline \multicolumn{6}{|l|}{ Physical examination Hydration status } \\
\hline No or slight dehydration & $31 / 71$ & 44 & $14 / 38$ & 37 & \multirow[t]{2}{*}{0.8} \\
\hline Moderate or severe dehydration & $40 / 71$ & 56 & $24 / 38$ & 63 & \\
\hline Abdominal pain on palpation & $35 / 66$ & 53 & $24 / 39$ & 50 & 0.8 \\
\hline \multicolumn{6}{|l|}{ Haematology } \\
\hline Leukocytosis & $42 / 68$ & 62 & $33 / 37$ & 89 & 0.003 \\
\hline Neutrophilia & $32 / 68$ & 47 & $26 / 35$ & 74 & 0.008 \\
\hline Monocytosis & $36 / 70$ & 51 & $30 / 37$ & 81 & 0.003 \\
\hline SIRS positive status & $36 / 71$ & 51 & $30 / 39$ & 77 & 0.007 \\
\hline Prolonged hospitalization (>=3 days) & $25 / 69$ & 36 & $9 / 37$ & 24 & 0.2 \\
\hline
\end{tabular}

SIRS Systemic inflammatory response syndrome

* Chi-square test/Fisher's exact test

Table 4 Clinical and laboratory findings in 72 dogs with open cervix pyometra and 39 dogs with closed cervix pyometra

\begin{tabular}{|c|c|c|c|c|}
\hline & $\begin{array}{l}\text { Open cervix pyometra Median } \\
\text { (interquartile range) }\end{array}$ & $\begin{array}{l}\text { Closed cervix pyometra Median } \\
\text { (interquartile range) }\end{array}$ & $p$ value * & Reference range $^{\mathrm{a}}$ \\
\hline $\mathrm{Hb}(\mathrm{g} / \mathrm{L})$ & $122.0(113.0-144.0)$ & 137.0 (116.0-152.0) & 0.1 & 132.0-199.0 \\
\hline PCV (\%) & $35.0(32.0-40.0)$ & $38.5(32.0-43.0)$ & 0.1 & $38.0-57.0$ \\
\hline WBC $\left(\times 10^{9} / \mathrm{L}\right)$ & $16.9(10.8-27.0)$ & $23.1(18.0-33.7)$ & 0.006 & $5.8-16.0$ \\
\hline Neutrophils $\left(\times 10^{9} / \mathrm{L}\right)$ & $10.9(7.4-16.8)$ & $15.5(11.1-21.8)$ & 0.005 & $3.0-11.5$ \\
\hline Band neutrophils $\left(\times 10^{9} / L\right)$ & $1.6(0.6-5.4)$ & $2.3(1.2-4.4)$ & 0.5 & $0.0-0.3$ \\
\hline Lymphocytes $\left(\times 10^{9} / \mathrm{L}\right)$ & $1.4(0.9-2.1)$ & $1.4(1.0-2.3)$ & 0.2 & $1.4-4.8$ \\
\hline Monocyte $\left(\times 10^{9} / \mathrm{L}\right)$ & $1.6(0.7-3.4)$ & $2.2(1.7-4.0)$ & 0.008 & $0.2-1.4$ \\
\hline Eosinophils $\left(\times 10^{9} / \mathrm{L}\right)$ & $0.2(0-0.5)$ & $0.1(0-0.4)$ & 0.8 & $0.1-1.2$ \\
\hline Basophils (×109/L) & 0 & 0 & 0.2 & $0.0-0.1$ \\
\hline Bile acids ( $\mu \mathrm{mol} / \mathrm{L})$ & $1.8(1.2-4.3)$ & $3.7(1.7-10.0)$ & 0.2 & $0.0-12.0$ \\
\hline ALT ( $\mu$ kat/L) & $0.4(0.3-0.6)$ & $0.3(0.2-0.4)$ & 0.2 & $0.0-1.3$ \\
\hline ALP ( $\mu k a t / L)$ & $3.4(1.9-5.1)$ & $4.3(2.1-6.4)$ & 0.3 & $<5.0$ \\
\hline ALB (g/L) & $26.0(22.0-28.0)$ & $26.0(24.0-30.0)$ & 0.2 & $29.0-39.0$ \\
\hline Glucose (mmol/L) & $5.1(4.4-5.9)$ & $4.7(4.2-5.2)$ & 0.06 & $4.5-5.8$ \\
\hline BUN (mmol/L) & $3.6(2.8-5.5)$ & $3.5(2.6-5.2)$ & 0.7 & $2.5-8.8$ \\
\hline Serum creatinine $(\mu \mathrm{mol} / \mathrm{L})$ & $67.0(57.0-75.0)$ & $74.0(63.0-82.0)$ & 0.1 & $40.0-130.0$ \\
\hline
\end{tabular}

Hb Haemoglobin, PCV Packed cell volume (haematocrit), WBC Total white blood cell count, ALT Alanine aminotransferase, ALP Alkaline phosphatase, ALB Albumin, BUN Blood urea nitrogen

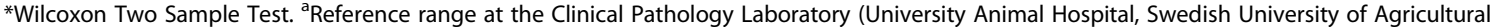
Sciences, Uppsala) 
creatinine concentrations is in agreement with findings in other studies of dogs with the disease $[9,11,15,18]$. None of the other clinical parameters analyzed differed significantly between the two groups in the present study.

The mortality in the surgically treated dogs was $4.5 \%$ ( $n=5 / 111)$ which was slightly higher than in our previous study where $1 \%$ of 315 surgically treated pyometra dogs died [9]. This difference between studies might reflect individual differences in disease severity among the included dogs. Peritonitis was the most common complication in the dogs with pyometra studied here, present in $10 \%$ of the bitches, which is in agreement with the proportion reported in our previous study [9].

A limitation of the present study was the number of included dogs, because a larger study is necessary to identify minor differences in variables between the groups and for rarer variables such as mortality. Data from 22 dogs were also included in our previous retrospective study of 356 dogs, i.e. the results in both these studies are not completely independent. Grading of the general physical condition is somewhat subjective and was performed by several veterinarians filling in a similar protocol, which also is a study limitation.

\section{Conclusion}

Dogs with closed cervix pyometra were more severely affected by the disease compared to dogs with open cervix pyometra as indicated by the more common finding of sepsis, leukocytosis, neutrophilia, monocytosis, and having moderately to severely depressed general condition in this group. Furthermore, total white blood cell count (WBC), segmented neutrophils and monocyte numbers were significantly higher in dogs with closed cervix pyometra. The present study thus provides, for the first time, data showing that closed cervix in dogs with pyometra is associated with more severe general illness at admission but not with increased postoperative hospitalization. This information might be valuable in clinical practice so that veterinarians are aware of a potentially more severe disease in dogs with closed cervix pyometra and that more intensive monitoring and treatment might be necessary to ensure a favourable outcome also in these dogs.

\section{Methods}

\section{Study design}

Clinical data, previously collected for two research studies were used for the analyses.

\section{Animals}

Prospectively collected data from 111 female dogs diagnosed with pyometra at the University Animal Hospital (UDS), Swedish University of Agricultural Sciences
(SLU), Uppsala, Sweden, intermittently during 20052012 was included.

The veterinarian in charge performed a complete physical examination and recorded case history and clinical examination data in a special study form which indicated the criteria categories for assessment. Case history, physical examination findings, laboratory test results together with evaluation by diagnostic imaging (radiography or/and ultrasonography) indicated a preliminary diagnosis of pyometra. All dogs were admitted to and treated by ovariohysterectomy at the University Animal Hospital (UDS), Swedish University of Agricultural Sciences (SLU), Uppsala. Written owner consent and daytime admission (Clinical Pathology Laboratory access) was a prerequisite for inclusion in the study. The definite diagnosis of dogs with pyometra was based on postoperative macroscopic identification of a pus-filled uterus, positive bacterial culture from the uterine content and histopathological examination of formaldehydefixated uteri and ovaries. Bitches with a histopathological diagnosis of mucometra, hydrometra or cystic endometrial hyperplasia were excluded [2].

Body temperature (BT), heart rate (HR), respiratory rate $(\mathrm{RR})$, mucus membrane color, capillary refilling time (CRT), abdominal pain on palpation (absent, mild, moderate or severe), its location, hydration status and general physical condition/appearance (normal i.e. bright, alert and responsive; mildly depressed, moderately depressed, severely depressed or very severely depressed/ non responsive as determined by the veterinarian in charge and also with consideration of the owner's statement of how the dogs normally appears and acts) were recorded at the time of admission.

After surgical treatment, dogs with pyometra generally require postoperative care and monitoring at the UDS, SLU, for 1-2 days provided that no complications occur. Postoperative hospitalization of 3 days or more, because of specific complications or depressed general physical condition was defined as prolonged.

\section{Blood collection and laboratory analyses Haematological and, biochemical analyses}

Blood samples were aseptically collected for haematology and clinical biochemistry from the distal cephalic vein and transferred into EDTA and non-additive collection tubes (Vacutainer, Becton-Dickinson, Stockholm, Sweden). The centrifugation was performed by using the blood collected in the non-additive tubes. The separated serum was used for analysing clinical biochemistry parameters. Clinical biochemical included Bile acids, Alanine aminotransferase (ALT), Glucose, Blood urea nitrogen (BUN), and Creatinine were measured (Abbott Architect c4000, Abbott Park, IL, USA). Haematological analyses (WBC including differential counts, haematocrit 
(PCV) and haemoglobin (Hb)) were performed (Advia 2120; Siemens Healthcare Diagnostics, Deer-field, IL, USA). Colorimetric method (bromocresol green) was used to analyse albumin and measured by using an automated analyser (Abbott Architect c4000, Abbott Park, IL, USA). All laboratory analyses were performed according to the routine methods at the Clinical Pathology Laboratory, UDS, SLU, Uppsala, Sweden.

\section{Definition of the systemic inflammatory response syndrome}

Systemic inflammatory response syndrome, SIRS, was classified using the criteria defined by Hauptman and others [22]. Dogs fulfilling two or more of the following criteria were defined as SIRS positive for the purpose of data analyses (1): Body temperature $(\mathrm{BT})<38.1^{\circ} \mathrm{C}\left(100.4^{\circ}\right.$ F) or $>39.2^{\circ} \mathrm{C}\left(102.6{ }^{\circ} \mathrm{F}\right)$; (2) Heart rate $(\mathrm{HR})>120$ beats per min; (3) Respiratory rate (RR) $>20$ breaths per minute; and Total white blood cell count $(\mathrm{WBC})<6$ or $>16 \times 10^{3} /$ $\mu \mathrm{L}$, or percentage band neutrophils $(\mathrm{PBN})>3 \%$.

\section{Statistical analyses}

The SAS program (version 9.3, SAS Institute Inc., Cary, NC, USA) was used for all analyses. Univariable associations between case history, physical examination and laboratory data, risk for prolonged hospitalization and risk of developing SIRS were analysed by Chi-Square test and Fisher's exact test for comparing between dogs with closed or open cervix pyometra. For continuous variables, the Wilcoxon Two Sample Test was used to test the difference between the two groups. Dogs with moderately to severely depressed general physical condition were grouped together in the analyses due to few dogs with severe depression and none with very severe depression or that were non-responsive. $P<0.05$ was set as significance level for differences between the two groups.

\section{Acknowledgements}

Not applicable.

\section{Funding}

Financial supports were obtained by Agria Pet Insurance's and Swedish Kennel Club's Research Foundation, The Thure F. and Karin Forsberg's Foundation.

\section{Availability of data and materials}

Not applicable due to patient confidentiality regulations, but may be available by personal request.

\section{Authors' Contributions}

SJ drafted the manuscript. SJ, RH, AA provided data and managed the data records. UE performed the statistical analyses together with SJ. All authors reviewed actively the manuscript during its preparation. All authors read and approved the final manuscript.

\section{Competing interests}

The authors declare that they have no competing interes.
Consent to publication

Not applicable.

\section{Ethics approval and consent to participate}

Data collected previously as approved by the Uppsala Local Ethical Board (permission number C191/5, C242/7, C325/11), were used for the analyses. A signed owner consent form was obtained before inclusion of any dog in the study.

Received: 22 October 2015 Accepted: 10 December 2016

Published online: 05 January 2017

\section{References}

1. Jitpean S, Hagman R, Holst BS, Hoglund OV, Pettersson A, Egenvall A. Breed Variations in the Incidence of Pyometra and Mammary Tumours in Swedish Dogs. Reprod Domest Anim. 2012;47:347-50.

2. Jitpean S, Holst BS, Hoglund OV, Pettersson A, Olsson U, Strage E, Sodersten F, Hagman R. Serum insulin-like growth factor-I, iron, C-reactive protein, and serum amyloid $\mathrm{A}$ for prediction of outcome in dogs with pyometra. Theriogenology. 2014;82(1):43-8.

3. Fransson BA, Lagerstedt AS, Bergstrom A, Hagman R, Park JS, Chew BP, Evans MA, Ragle CA. C-reactive protein, tumor necrosis factor alpha, and interleukin-6 in dogs with pyometra and SIRS. J Vet Emerg Crit Care. 2007; 17(4):373-81.

4. Hagman R, Reezigt BJ, Ledin HB, Karlstam E. Blood lactate levels in 31 female dogs with pyometra. Acta Vet Scand. 2009;51(2):9.

5. Levy MM, Fink MP, Marshall JC, Abraham E, Angus D, Cook D, Cohen J, Opal SM, Vincent JL, Ramsay G, et al. 2001 SCCM/ESICM/ACCP/ATS/SIS International Sepsis Definitions Conference. Crit Care Med. 2003;31(4):1250-6.

6. Hagman R, Greko C. Antimicrobial resistance in Escherichia coli isolated from bitches with pyometra and from urine samples from other dogs. Vet Rec. 2005:157(7):193-6.

7. Vandeplassche M, Coryn M, Deschepper J. Pyometra in the bitchcytological, bacterial, histological and endocrinologic characteristics. Vlaams Diergen Tijds. 1991;60(6):207-11.

8. Egenvall A, Hagman R, Bonnett BN, Hedhammar A, Olson P, Lagerstedt AS. Breed risk of pyometra in insured dogs in Sweden. J Vet Intern Med. 2001; 15(6):530-8.

9. Jitpean S, Strom-Holst B, Emanuelson U, Hoglund OV, Pettersson A, AlnerydBull C, Hagman R. Outcome of pyometra in female dogs and predictors of peritonitis and prolonged postoperative hospitalization in surgically treated cases. BMC Vet Res. 2014;10(1):6.

10. Macphail C. Pyometra. In: Fossum T, editor. Small Animal Surgery. 4th ed. Missouri: Elsevier Inc; 2013. p. 818-24.

11. Kuplulu S, Vural MR, Demirel A, Polat M, Akcay A. The comparative evaluation of serum biochemical, haematological, bacteriological and clinical findings of dead and recovered bitches with pyometra in the postoperative process. Acta Vet-Beograd. 2009;59(2-3):193-204.

12. Borresen B. Pyometra in the dog- a pathophysiological investigation. II. Anamnestic, clinical and reproductive aspects. Nord Vet Med. 1979:31(6):251-7.

13. Fransson B, Lagerstedt AS, Hellmen E, Jonsson P. Bacteriological findings, blood chemistry profile and plasma endotoxin levels in bitches with pyometra or other uterine diseases. J Vet Med A. 1997;44(7):417-26.

14. Asheim A. Renal function in dogs with pyometra- uterine infection and pathogenesis of renal dysfucntion. Acta Path Micro. 1964;60(1):99-107.

15. Borresen B, Skrede S. Pyometra in the dog- a pathophysiological investigation $\mathrm{V}$. The presence of intrahepatic cholestasis and an "acute phase reaction.". Nord Vet Med. 1980;32(9):378-86.

16. Plavec T, Celinsek B, Dolinar K, Pecar J, Nemec A, Butinar J. Haemostasis impairment in bitches with pyometra. Acta Vet-Beograd. 2006;56(5-6):529-40.

17. Smith FO. Canine pyometra. Theriogenology. 2006;66(3):610-2.

18. Jitpean S, Pettersson A, Hoglund OV, Holst BS, Olsson U, Hagman R. Increased concentrations of Serum amyloid $A$ in dogs with sepsis caused by pyometra. BMC Vet Res. 2014;10(273):9.

19. Hagman R, Lagerstedt AS, Fransson BA, Bergstrom A, Haggstrom J. Cardiac troponin I levels in canine pyometra. Acta Vet Scand. 2007;49:6.

20. Sun D, Aikawa N. The natural history of the systemic inflammatory response syndrome and the evaluation of SIRS criteria as a predictor of severity in 
patients hospitalized through emergency services. Keio J Med. 1999;48(1):28-37.

21. Afessa B. Systemic inflammatory response syndrome in patients hospitalized for gastrointestinal bleeding. Crit Care Med. 1999:27(3):554-7.

22. Hauptman JG, Walshaw R, Olivier NB. Evaluation of the sensitivity and specificity of diagnostic criteria for sepsis in dogs. Vet Surg. 1997;26(5):393-7.

23. Lennard ES, Minshew BH, Dellinger EP, Wertz M. Leukocytosis at termination of antibiotic therapy-its importance for intra-abdominal surgery. Arch Surg. 1980;115(8):918-21.

24. Lennard ES, Dellinger EP, Wertz MJ, Minshew BH. Implications of leukocytosis and fever at conclusion of antibiotics- therapy for intraabdominal sepsis. Ann Surg. 1982;195(1):19-24.

25. Delabry LO, Campion EW, Glynn RJ, Vokonas PS. White blood cell count as a predictor of mortality- results over 18 years from the normative aging study. J Clin Epidemiol. 1990:43(2):153-7.

26. Moghadamyeghaneh Z, Hanna MH, Carmichael JC, Mills SD, Pigazzi A, Stamos MJ. Preoperative Leukocytosis in Colorectal Cancer Patients. J Am Coll Surgeons. 2015;221(1):207-14.

27. Diekema DJ, Beekmann SE, Chapin KC, Morel KA, Munson E, Doern GV. Epidemiology and outcome of nosocomial and community-onset bloodstream infection. J Clin Microbiol. 2003:41(8):3655-60.

28. Lucroy MD, Madewell BR. Clinical outcome and associated diseases in dogs with leukocytosis and neutrophilia: 118 cases (1996-1998). JAVMA. 1999; 214(6):805-7.

\section{Submit your next manuscript to BioMed Central} and we will help you at every step:

- We accept pre-submission inquiries

- Our selector tool helps you to find the most relevant journal

- We provide round the clock customer support

- Convenient online submission

- Thorough peer review

- Inclusion in PubMed and all major indexing services

- Maximum visibility for your research

Submit your manuscript at www.biomedcentral.com/submit 